\title{
OPTICAL PROPERTIES OF CANADIAN BIOMASS BURNING PARTICLES OVER EUROPE OBSERVED WITH CALIPSO AND GROUND-BASED LIDAR SYSTEMS

\author{
Christina-Anna Papanikolaou ${ }^{1,2^{*}}$, Elina Giannakaki ${ }^{1,3}$, Alex Papayannis ${ }^{2}$, Maria Tombrou ${ }^{1}$, Maria \\ Mylonaki $^{1,2}$ and Ourania Soupiona ${ }^{2}$
}

\author{
${ }^{1}$ Department of Environmental Physics and Meteorology, Faculty of Physics, National and Kapodistrian \\ University of Athens, 15772 Zografou, Greece \\ ${ }^{2}$ Laser Remote Sensing Unit, Physics Department, School of Applied Mathematics and Physical Sciences, \\ National Technical University of Athens, 15780 Zografou, Greece \\ ${ }^{3}$ Finnish Meteorological Institute, Kuopio, Finland \\ *Email: papanikolaou.christiann@gmail.com
}

\begin{abstract}
A long-lasting biomass burning event affected Europe from 27 August to 3 September 2018. The biomass burning aerosol layers were observed with groundand space-based lidars in heights ranged between 2-7 $\mathrm{km}$ (a.s.1.). The mean backscatter coefficient for the ground-based stations ranged between 0.29 and 1.51 $\mathrm{Mm}^{-1} \mathrm{sr}^{-1}$, while the CALIPSO retrieved values ranged between 0.43 and $1.83 \mathrm{Mm}^{-1} \mathrm{sr}^{-1}$. Moreover, the mean Ångström exponent $\left(\mathrm{AE}_{\mathrm{b}}\right)$ values, relevant to backscatter, ranged from 0.83 to 1.04 for the aforementioned lidar stations. At the same time, the mean $\mathrm{AE}_{\mathrm{b}}$ values obtained from CALIPSO ranged between 0.17 and 1.89 . The mean particle depolarization ratio ranged between 0.037 and 0.080 .
\end{abstract}

\section{INTRODUCTION}

Biomass burning particles (BBPs) through interactions with radiation and clouds play an important role in the Earth's climate system as they scatter and absorb solar radiation (so-called direct effect) while influencing the cloud processes as cloud condensation nuclei (CCN) (so called indirect effect) [1-3].

Forest fires are a significant source of BBPs, especially at northern latitudes especially in spring and summer period [4]. It has been shown that large smoke plumes from large forest fires can be injected into the free troposphere, and then easily transported by air masses along the Earth [1,5-6].

In this context, the CALIPSO (Cloud-Aerosol Lidar and Infrared Pathfinder Satellite Observation) mission provides the opportunity to represent the fourdimensional distribution of aerosols and clouds, offering global coverage with high spatial resolution [8]. Nevertheless, CALIPSO observations offer only snapshots and therefore only the synergic use with terrestrial systems, passive remote sensing measurements and models allows a detailed description of the spatial and temporal distribution of biomass burning long transport incidents and its evolution on a global scale.

In order to increase and validate the accuracy of aerosol optical properties retrieved from CALIPSO's products, a comparison with ground-based lidar observations is required. Thanks to its geographic coverage and the deployment of advanced Raman aerosol lidars, EARLINET offers a unique opportunity for the validation of the CALIPSO $[7,8]$.

In this contribution, we study an extreme biomass burning aerosol event, in terms of geometrical and optical properties of the biomass burning plume. Wildfires started in August 2018 from the Canadian Province of British Columbia, causing enormous forest areas to burn up. The BBPs travelled across the Atlantic Ocean and affected Europe between $26^{\text {th }}$ of August and early September. The event was studied with the synergy of data from the CALIOP (CloudAerosol Lidar with Orthogonal Polarization) lidar system on board the CALIPSO satellite, the EARLINET network, the NASA's tool Giovanni and the HYSPLIT (Hybrid Single-Particle Lagrangian Integrated Trajectory) model.

\section{METHODOLOGY}

\subsection{CALIOP lidar System}

CALIPSO is an Earth Science observation mission that was launched on 28 April 2006. It flies at a nominal orbital altitude of $705 \mathrm{~km}$. The CALIPSO mission includes active lidar and passive sensors to obtain unique data on aerosol and cloud vertical structure, cloud particle phase and classification of the aerosol size.

CALIOP is an elastically backscattered lidar operating at 532 and $1064 \mathrm{~nm}$, equipped with a depolarization channel at $532 \mathrm{~nm}$ that provides high-resolution vertical profiles of aerosols and clouds $[9,10]$. The Level 2 CALIPSO products include a cloud layer product, an aerosol layer product and an aerosol profile product (backscatter, extinction, and depolarization ratio) [11]. In this study, the aerosol 
optical properties reported in the Level 2 products (version 3.40) are used.

\subsection{Passive satellite products}

The Moderate Resolution Imaging Spectroradiometer (MODIS), a major NASA EOS instrument, was launched aboard the Terra satellite in 1999 for global monitoring of the atmosphere, terrestrial ecosystems, and oceans, while in 2002, a similar instrument was launched on the EOS-Aqua. MODIS, flying on two satellites in orbits that complement each other, provide the diurnal variation of the rapidly varying parameters for the study of climate and global change studies [12].

Giovanni is an online tool for visualization, exploration, and analysis of NASA Earth Science data. Atmospheric Optical Depth (AOD) observations from several instruments can be accessed through Giovanni. Total and fine mode AOD from MODIS, as well as from other instruments are available [13]. The Giovanni tool was used to verify the path of smoke's motion and represent the AOD at $550 \mathrm{~nm}$, according to MODIS (Aqua \& Terra) data for temporal resolution equal to one day and spatial resolution of $1^{\circ}$ (not shown here).

\subsection{Ground-based lidar stations}

Four ground-based lidar stations, within EARLINET, were selected based on their data availability at time periods that CALIOP detected smoke over Europe. The stations, along with their geophysical coordinates and the available data products, are presented in Table 1 [8]. The corresponding profiles of the aerosol backscatter $(\beta)$ and extinction $(\alpha)$ coefficients, $\mathrm{AE}_{\mathrm{b}, \mathrm{a}}$ and depolarization ratio $(\delta)$ of ground-based lidar measurements were used to validate the space-borne products for this biomass burning event.

Table 1: Location and available data products for 4 EARLINET stations used in this study.

\begin{tabular}{|cc|}
\hline \multicolumn{2}{|c|}{ EARLINET stations } \\
\hline Location & $\begin{array}{c}\text { Data Products } \\
\text { Available }\end{array}$ \\
\hline Athens, Greece & $\beta(532,1064 \mathrm{~nm})$ \\
$37.96^{\circ} \mathrm{N}, 23.78^{\circ} \mathrm{E}(212 \mathrm{~m}$ a.s.1. $)$ & $\delta(355 \mathrm{~nm})$ \\
\hline Leipzig, Germany & $\beta(532,1064 \mathrm{~nm})$ \\
$51.35^{\circ} \mathrm{N}, 12.43^{\circ} \mathrm{E}(90 \mathrm{~m}$ a.s.1. $)$ & $\alpha(532 \mathrm{~nm})$ \\
\hline Madrid, Spain $^{\circ}$ & $\beta(532,1064 \mathrm{~nm})$ \\
$40.456^{\circ} \mathrm{N}, 3.729^{\circ} \mathrm{W}(669 \mathrm{~m}$ a.s.1. $)$ & $\alpha(532,1064 \mathrm{~nm})$ \\
\hline Thessaloniki, Greece $_{4}$ & $\beta(532,1064 \mathrm{~nm})$ \\
$40.6300^{\circ} \mathrm{N}, 22.9500^{\circ} \mathrm{E}(50 \mathrm{~m}$ a.s.1. $)$ & $\alpha(532 \mathrm{~nm})$ \\
\hline
\end{tabular}

\subsection{Trajectory Analysis}

The analysis of the forward trajectories was performed using the ensemble calculation of HYSPLIT model $[14,15]$. Multiple trajectories start from the selected starting point, and each member of the trajectory ensemble is calculated by offsetting the meteorological data by a fixed grid factor, resulting in 27 members for all-possible offsets in longitude, latitude and altitude. The 12-day-forward analysis was performed for each one of the days that active fires and smoke were observed upon Canada. As long as the aerosol layers over Canada identified as smoke by CALIPSO, their coordinates and altitude were used as initial values for the model.

\section{RESULTS}

\subsection{CALIPSO smoke observation}

Active fires in the Canadian region were detected by CALIOP and MODIS, between 16 and 22.08.2018 as presented in Figures 1 and 2.

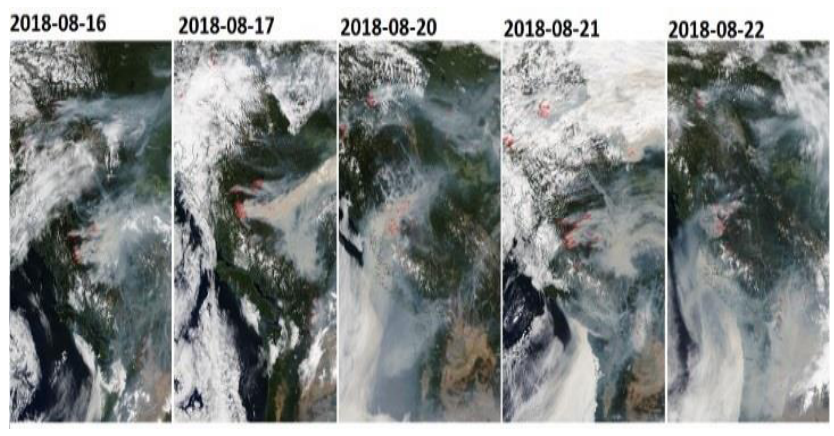

Figure 1. Active fires and smoke detected in British Columbia, Canada during 16-22 August 2018 (Terra and Aqua/ MODIS).

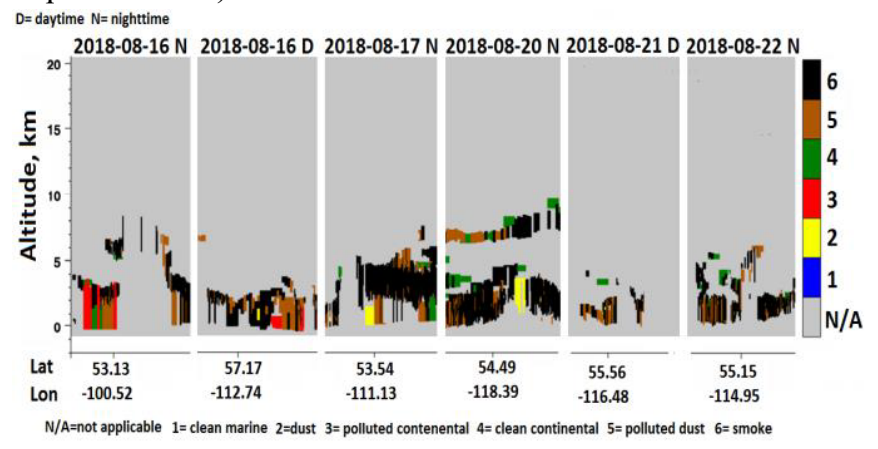

Figure 2. Different types of the aerosol layers detected by CALIPSO for each of the overpasses upon British Columbia, Canada, during 16-22 August 2018. Black color indicates smoke aerosol particles.

The Canadian wildfire plume has traveled in the free troposphere and reached Europe several days later. The aerosol layers were detected by CALIOP and four EARLINET stations [Athens (Greece), Leipzig (Germany), Madrid (Spain) and Thessaloniki Greece)]. These ground-based stations have been used for comparison with CALIPSO Level 2 version 3.40 aerosol products on 27, 29, 30 August and 03 September 2018 (Figs. 3-4).

As shown in Fig. 4, the CALIOP observations show aerosol layers in the $2-7 \mathrm{~km}$ altitude range above 


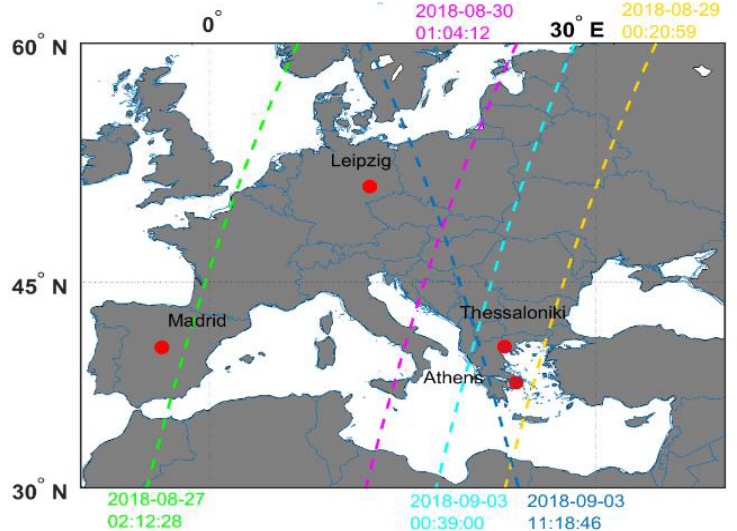

Figure 3. CALIPSO orbits on 27, 29, 30 August and 03 September 2018. Red dot correspond to Athens, Leipzig, Madrid and Thessaloniki lidar stations.

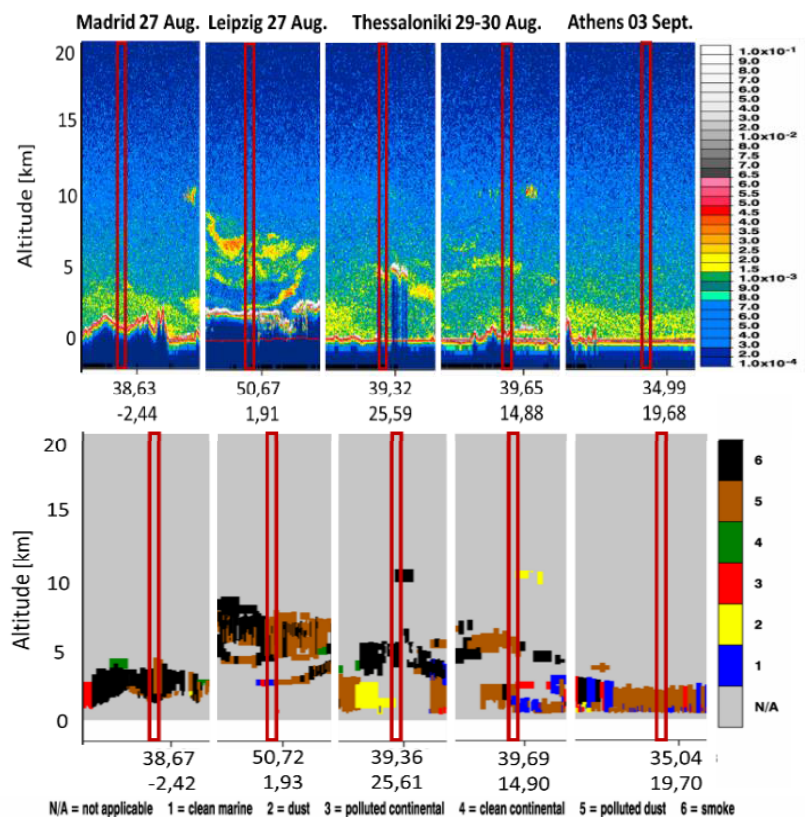

Figure 4. CALIPSO total attenuated backscatter at 532 $\mathrm{nm}$ and aerosol subtyping, for each of the overpasses tracking the masses arriving at Madrid, Leipzig, Thessaloniki and Athens. Red lines correspond to the nearest overpass over each lidar station.
Europe. According to subtyping, aerosol layers correspond to smoke particles and particles of polluted dust (dust mixed with smoke) [16].

Moreover, Satellite observations from MODIS instrument, NASA's tool GIOVANNI, as well as modeling tools such as HYSPLIT, have been used to estimate transport paths and the source of those forest fire smoke particles (not shown here).

\subsection{Comparison of CALIPSO and EARLINET optical profiles}

In principle, all CALIPSO level 2 data can be directly compared with EARLINET data for nearby overpasses and stations providing data at 532 and $1064 \mathrm{~nm}$ [7]. For the period from 27 August to 03 September for every station with available data through CALIPSO overpasses, the vertical profiles of aerosol optical properties compared to the ones of CALIPSO are plotted. The CALIPSO aerosol retrievals are performed at 5, 25, 45 and $105 \mathrm{~km}$ spatial resolution. Indicatevely, the profiles for Madrid and Athens lidar stations are presented in Figs. 5-6.

CALIPSO overpassed Madrid during the night of $27^{\text {th }}$ of August, the minimum distance from the orbit equals to $123.878 \mathrm{~km}$. The aerosol layer observed both from CALIOP and ground-based station, ranged between 2 and $3.5 \mathrm{~km}$, was attributed to smoke particles, with a value of $0.95 \pm 0.05 \mathrm{Mm}^{-1} \mathrm{sr}^{-1}$ for the backscatter coefficient while the mean value measured by Madrid station was equal to $1.03 \pm 0.02 \mathrm{Mm}^{-1} \mathrm{sr}^{-1}$. The agreement between the two coefficients, calculated in (\%) (CALIPSO-EARLINET/EARLINET), gives a $7.8 \%$ difference. The extinction coefficient at $532 \mathrm{~nm}$ was equal to $62.1 \pm 4.6 \mathrm{Mm}^{-1}$ and $41.2 \pm 0.7 \mathrm{Mm}^{-1}$ measured by CALIPSO and ground-based station respectively. The mean backscatter-related Ångström

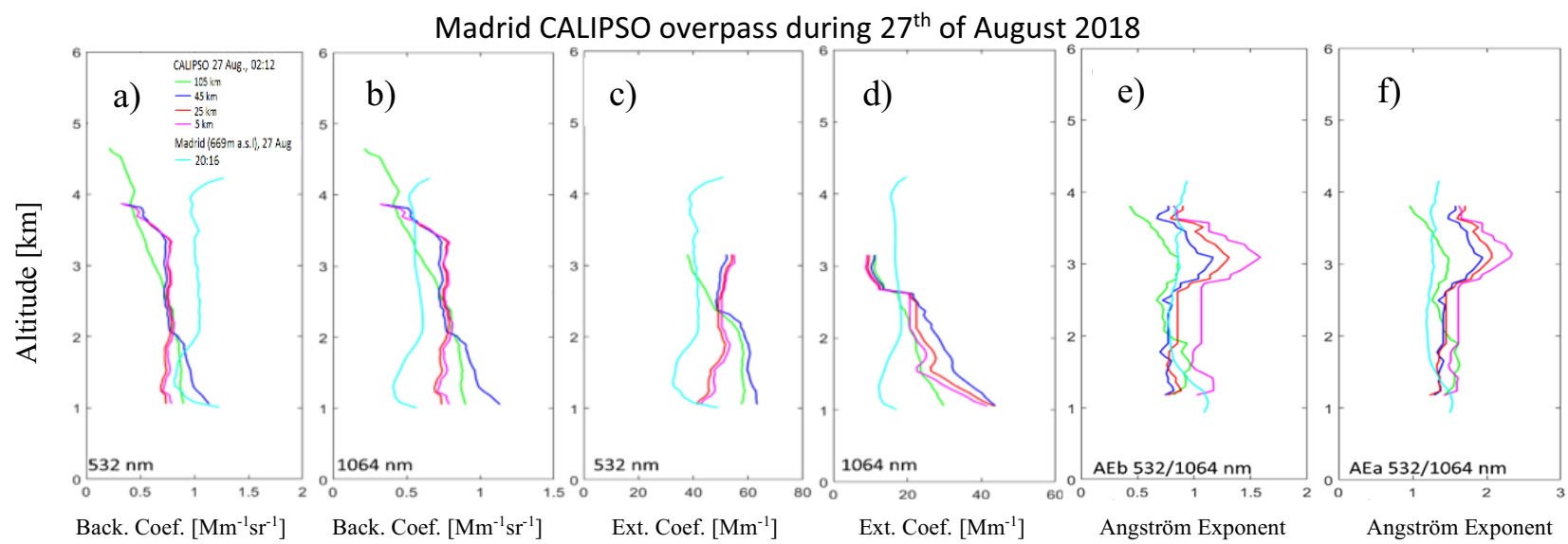

Figure 5: Aerosol backscatter coefficient profiles at 532 and $1064 \mathrm{~nm}(\mathrm{a}, \mathrm{b})$, extinction coefficient profiles at 532 and $1064 \mathrm{~nm}$ (c,d), backscatter and extinction Ångström exponent at 532/1064 nm (e,f), measured over Madrid station on 27 August (20.16 UTC) and the corresponding profiles at 532 and $1064 \mathrm{~nm}$ derived from CALIPSO on 27 August ( 02.12 UTC). 


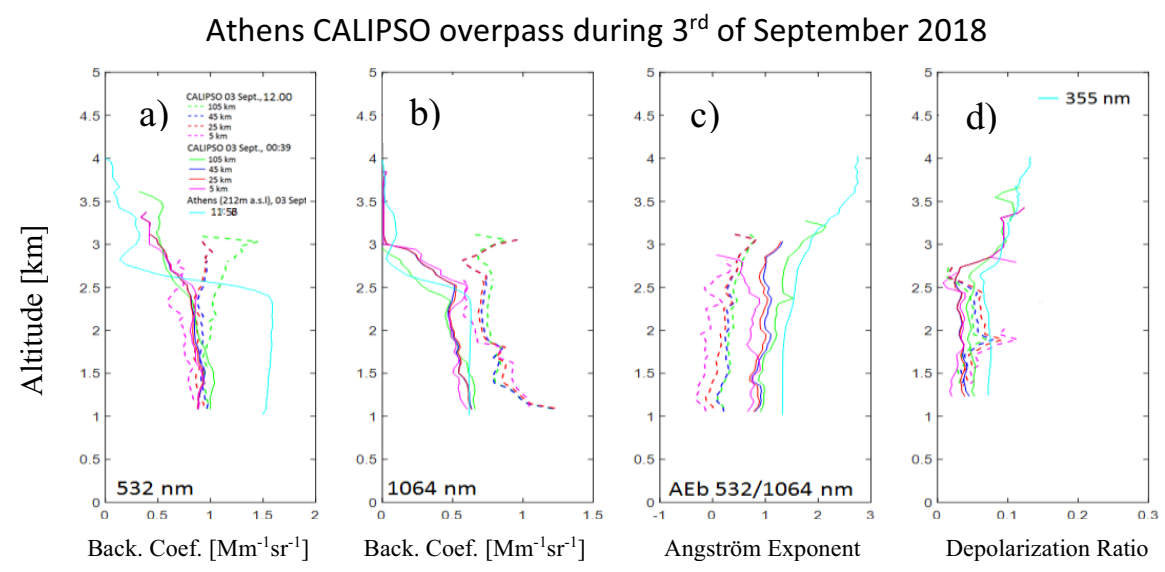

Figure 6: Aerosol backscatter coefficient profiles at 532 and $1064 \mathrm{~nm}(\mathrm{a}, \mathrm{b})$, Angström exponent at 532/1064 nm (c) and particle depolarization ratio at $355 \mathrm{~nm}(\mathrm{~d})$, measured at Athens station on 03 September (11.58 UTC). The dashed lines correspond to profiles at 532 and $1064 \mathrm{~nm}$ derived from daytime CALIPSO orbit on 03 September (12.00 UTC), while the continuous lines from nighttime orbit (00.45 UTC).

exponent value from CALIPSO was $0.86 \pm 0.15$ while in Madrid station had a mean value of $0.83 \pm 0.04$. The mean extinction-related Ångström exponent value from CALIPSO was $1.45 \pm 0.13$ while in ground-based station had a mean value of $1.24 \pm 0.04$.

During the CALIPSO overpass over Athens on 3 September, the minimum distance from the daytime and nighttime orbit was 173.253 and $275.387 \mathrm{~km}$, respectively. Two mixed biomass burning aerosol layers were observed between 2 and $2.5 \mathrm{~km}$ and between 3 and $3.5 \mathrm{~km}$ height. The mean value of the aerosol backscatter coefficient for the $2 \mathrm{~km}$-layer, obtained from both orbits was found equal to $0.88 \pm 0.11 \mathrm{Mm}^{-1} \mathrm{sr}^{-1}$ and $0.43 \pm 0.03 \mathrm{Mm}^{-1} \mathrm{sr}^{-1}$ for the 3 $\mathrm{km}$-layer, while the corresponding value measured by Athens station was $1.51 \pm 0.08 \mathrm{Mm}^{-1} \mathrm{sr}^{-1}$ and $0.29 \pm 0.10$ $\mathrm{Mm}^{-1} \mathrm{Sr}^{-1}$, respectively. The agreement between these coefficients, calculated in (\%), gives a $42 \%$ for the lower layer and a 48\% difference between CALIPSO and the ground-based station. The mean value of the $\mathrm{AE}_{\mathrm{b}}$ obtained by CALIPSO ranged from 0.17 to 1.89 , while the same parameter for the ground based system was $1.54 \pm 0.37$. The mean particle depolarization ratio of 0.075 measured at Athens station, agrees with the CALIPSO value of 0.080 .

\section{ACKNOWLEDGMENTS}

We acknowledge support of this work by the project "PANhellenic infrastructure for Atmospheric Composition and climatE change" (MIS 5021516) which is implemented under the Action "Reinforcement of the Research and Innovation Infrastructure", funded by the Operational Programme \& Competitiveness, Entrepreneurship and Innovation \& (NSRF 2014-2020) and co-financed by Greece and the European Union (European Regional Development Fund). Part of this research has been cofinanced by additional funding from the European
Union $7^{\text {th }}$ Framework Programme (FP7/2007-2013) under grant agreement No 262254.

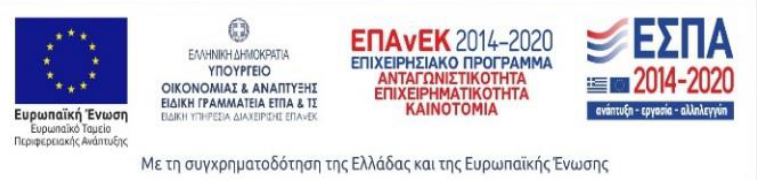

REFERENCES

[1] IPCC AR5, Summary for Policymakers (2013)

[2] P. Ortiz-Amezcua,et al., Atmos. Chem. Phys., 17, 5931-5946 (2017)

[3] I. McKendry, et al., Atmos. Chem. Phys., 11, 465477 (2011)

[4] S. Generoso, et al., Atmos. Chem. Phys., 3, 1211$1222(2003)$

[5] G. Ancellet, et al., Atmos. Chem. Phys., 16, 47254742 (2016)

[6] J. L. Guerrero-Rascado, et al., Proc. $26^{\text {th }}$ ILRC, July 5-9, 2010, St.-Petersburg, Russia (2010)

[7] G. Pappalardo, et al., J. Geophys. Res., 115, 148227 (2010)

[8] G. Pappalardo, et al., Atmos. Meas. Tech., 7, 2389-24092014 (2014)

[9] D. M. Winker, et al, Geophys. Res. Lett., 34 (2007)

[10] W.H Hunt, et al., J. Atmos. Oceanic Technol., 26, 1214-1228 (2009)

[11] R. E. Mamouri, et al., Atmos. Meas. Tech., 2, 513522 (2009)

[12]A. Savtchenko, et al., Advances in Space Research 34, 710-714 (2004)

[13]A. Prados, et al., IEEE J. Sel. Top. Appl. Earth Obs. Remote Sens., 3, 1939-1404 (2010)

[14] A. F. Stein, et al., Bull. Amer. Meteor. Soc., 96, 2059-2077 (2015)

[15]G. Rolph, et al, Env. Mod. \& Soft., 95, 210-228 (2017)

[16] A. H. Omar, et al., Jour. of Atm. and Ocean. Tech., 26, 1994-2014 (2009) 